\title{
The EFFect of STRESSEd Economic Conditions on CREDIT RISK IN BASEL II
}

\section{Ja'nel Esterhuysen}

Absa Capital: Investment Bank Division of Absa Bank and School of Economics, North-West University

Gary van Vuuren and Paul Styger

School of Economics, North-West University

Accepted September 2010

\begin{abstract}
The robustness of the Basel II accord in protecting banks during volatile economic periods has been challenged during the ongoing credit crisis. In particular, advanced approaches to measuring and managing credit risk have drawn criticism for being both irrelevant and too complex. Despite accusations that the accord was largely responsible for the crisis, this article explores which of Basel Il's credit risk approaches were more successful in allocating capital. It was found that, in general, compliance with Basel II actually protected banks during the crisis, with simpler approaches enjoying greater success than more advanced ones in protecting banks against credit risk.
\end{abstract}

Key words: credit risk, loss and frequency distributions, credit crisis, Basel II

JEL C46, G21, 32

\section{1}

Introduction

The global financial crisis, which began in June 2007, has been described as the most serious financial crisis since the Great Depression of the 1930s (Soros, 2008). It resulted in considerable international distress, with almost all major banks experiencing capital shortages, and some defaulting outright. Among the principal causes was an explosive increase, by a factor of ten in some cases, in credit defaults, (Subramanian, 2009) precipitated by lax lending standards, which had prevailed for several preceding years. An early victim, Northern Rock, a medium-sized UK bank, requested security from the Bank of England after its highly leveraged balance sheet led to investor panic and a bank run in midSeptember 2007. Although the plea was initially unsuccessful, the UK government did eventually relent and the bank, the first of many, was taken into public hands in February
2008 (Subramanian, 2009). Northern Rock's problems proved to be an early indication of the troubles that would soon beset other banks and financial institutions. Those initially affected, such as Northern Rock and Countrywide Financial, were directly involved in mortgage-lending and residential home construction, and short-term financing through increasingly illiquid credit markets became a virtual impossibility (Allen \& Bali, 2007). Over 100 mortgage lenders worldwide went bankrupt during 2007 and 2008, and concerns that the large investment bank Bear Stearns would collapse in March 2008 resulted in its 'fire-sale' to JP Morgan Chase. The credit crisis reached its peak during the months of September and October 2008 (Allen \& Bali, 2007). Global stock markets were slower to react: substantial losses were recorded throughout the early part of 2009, until the nadir was reached in mid-March of that year. The crisis caused the failure of several major institutions, which were subsequently acquired under duress): many of these were subject to 
takeover by their relevant sovereigns, including, amongst others, Lehman Brothers, Merrill Lynch, Fannie Mae, Freddie Mac and American International Group, AIG.

Catastrophic failures of inadequate capital allocation and management were exposed, and culpability for the cause, severity and duration of the crisis was placed on, inter alia, regulatory bodies, credit rating agencies and bank CEOs. Financial institutions began to question the validity and relevance of the underlying credit-risk principles forming the basis of the Basel II Accord (Basel II) issued by the Basel Committee on Banking Supervision (BCBS) in 2005 (BCBS, 2006a). These principles were devised to provide banks and other financial institutions, like insurance companies, with methods for managing credit risk adequately by providing guidance for assessing credit risk, including equations for determining risk capital for more advanced approaches. Because many institutions' capital levels proved woefully inadequate during the crisis, these principles are inevitably now being challenged (Colander, Follmer \& Haas, 2009:2). However, during December 2009, the BCBS approved for consultation a package of proposals for strengthening global capital and liquidity regulations with the goal of promoting a more resilient banking sector, which would form part of its response to addressing the lessons learned from the crisis and to strengthen the Basel II framework (BCBS, 2009).

Basel II provides two different approaches for the measurement and management of credit risk; the Standardised Approach (the simplest, hereafter referred to as the SA) and the Internal Ratings Based (IRB) approach. The IRB approach is divided into two further approaches of increasing complexity: the Foundation (FIRB) and the Advanced (AIRB) approaches. For the purpose of this study, both will be referred to collectively as the 'Advanced Approaches' (AA). The AA employs complex mathematical formulations, which are now under attack (Collander et al., 2009:2). This is because the AA allows banks to use their own internal models to assess credit risk and risk-sensitive capital adequacy levels. Many such models are mathematically complex and may be incapable of modelling the 'exceptional times' (a generic shortcoming of all mathematical models) experienced by the financial world during the credit crisis. It has been posited that financial engineers were aware of the unrealistic restrictions and severe limitations imposed on the models to ensure stability, but embraced them anyway. The fragility and unreliability of these models under stressed conditions has surprised many (Collander et al., 2009:2), although the severity, duration and contagion effect of the crisis admittedly did not seem feasible (Subramanian, 2009:3) and was thus not explicitly modelled prior to the eruption of the crisis.

Banks were perceived as being adequately capitalised prior to the credit crisis (Collander et al., 2009:2), and, by Basel II standards, this was certainly true despite the ensuing market mayhem, which revealed inadequate capitalisation. For example, Lehman Brothers, Merrill Lynch, Fannie Mae, Freddie Mac, American International Group and JP Morgan were regarded as being among the top 30 largest and most capitalised financial institutions in the world (Subramanian, 2009:3). The majority of banks referred to in this article had already been approved for the AIRB approach or were in the process of applying for it under Basel II (see Section 2). The question arises: Was Basel II's simpler approach to credit risk successful in guarding banks against credit risk catastrophes ${ }^{1}$ (through the adequate provision of buffer capital), or did Basel II's advanced credit risk approach succeed in protecting banks from disaster. This article addresses these questions by comparing bank credit-risk losses determined by using the Basel II Standardised approach to losses with losses incurred when the Basel II advanced approaches were used prior to and during ${ }^{2}$ the crisis. The question of whether or not the sophisticated mathematical approaches to the measurement and management of credit risk used in advanced approaches were more successful than the simpler approaches will be discussed.

The remainder of this paper is arranged as follows: Section 2 provides a brief literature study of the Basel II advanced credit risk approaches along with a brief overview of the major credit risk losses experienced during the 
crisis. A description of the data employed in the study is presented in Section 3 and the subsequent analysis of these data follows in Section 4. Section 5 concludes the paper.

2

\section{Literature review}

Basel II relies heavily on a number of key elements, which now appear to have weakened in light of the credit and liquidity crisis (Griffin, 2008:2). Firstly, Basel II promotes the use of complex internal quantitative modelling techniques by banks for the calculation of regulatory capital (Griffin, 2008:3) and there are concerns about the opacity of these models. Secondly, the new capital adequacy rules depend heavily on the research produced by credit-rating agencies. Given the culpability ascribed by many to the rating agencies in the structured credit market turmoil, should Basel II really give these agencies a quasi-regulatory role in relation to capital adequacy and counterparty credit risk assessment? Thirdly, despite improvements on Basel I, the new rules continue to focus on credit origination, rather than on new credit derivative instruments and structured products. Fourthly, the IMF recently stated that the pro-cyclical nature of Basel II capital requirements, which require banks to hold additional capital against greater anticipated losses as the economic cycle turns downward, could exacerbate an economic recession by forcing banks to restrict their provision of credit in a downturn scenario (Repullo \& Suarez, 2008) ${ }^{3}$. Lastly, the credit crunch was partly the result of a widespread lack of information, which exacerbated the initial US sub-prime problems.

While enhanced disclosure is one of the three pillars forming the basis of Basel II, it is recognised as the weakest in terms of both prescription and enforcement (Griffin, 2008:4). Basel II disclosure is required for external parties like Credit Rating Agencies (CRAs) and regulators to assess an individual bank's capital adequacy levels in order to provide the bank with some guidance. However, this disclosure was, in most cases, insufficient, which led to the inadequate assessment of capital by external parties and in turn to inadequate guidance on capital adequacy levels. Banks' capital bases could therefore not protect them against the systematic effects of the crisis. These capital levels and their disclosure should be aligned more with the way in which banks assess credit risk (Griffin, 2008:5).

Although it is not the focus of this paper, a summary of the different Basel II approaches can be seen in Figure 1, which highlights the major differences between these approaches and provides a good background for the remainder of this paper.

\section{Figure 1}

Brief overview of Basel II credit risk approaches

\begin{tabular}{|c|c|c|}
\hline Standardised & \multicolumn{2}{|c|}{ Internal ratings based (IRB) Approaches } \\
\hline $\begin{array}{l}\text { - Apply prescribed risk-weights } \\
\text { (which differ from Basel I) to } \\
\text { exposures residing in asset } \\
\text { classes to calculate RWA. } \\
\text { - Limited recognition of credit } \\
\text { mitigation (more than in Basel I). } \\
\text { Two options: } \\
\text { - Simple Approach: Substitution of } \\
\text { risk- weighted collateral for risk- } \\
\text { weighting of counterparty. } \\
\text { - Comprehensive Approach: } \\
\text { Calculate adjusted amount of } \\
\text { exposure and value of collateral, } \\
\text { using haircuts (standard super- } \\
\text { visory or own-estimate haircuts). }\end{array}$ & $\begin{array}{l}\text { Foundation (FIRB) Approach } \\
\text { - RWA are calculated using a } \\
\text { Basel II risk-weight formula } \\
\text { with the following inputs: } \\
\text { Probability of Default (PD), } \\
\text { Exposure at Default (EAD), } \\
\text { Loss Given Default (LGD) } \\
\text { and Effective Maturity (M). } \\
\text { - LGD (45 per cent for } \\
\text { unsecured), EAD and M is } \\
\text { prescribed by SARB. } \\
\text { - Larger range of credit } \\
\text { mitigation recognised. }\end{array}$ & $\begin{array}{l}\text { Advanced (AIRB) Approach } \\
\text { - RWA are calculated using a } \\
\text { Basel II risk-weight formula } \\
\text { or function using PD, EAD, } \\
\text { LGD and M as inputs. } \\
\text { - M is calculated in a similar } \\
\text { way to the duration of a bono } \\
\text { or the SARB allows the use } \\
\text { of contractual maturity. } \\
\text { - Range of credit mitigation } \\
\text { unlimited as long as the LGD } \\
\text { parameter estimate can be } \\
\text { proved based on sufficient } \\
\text { historical data. }\end{array}$ \\
\hline
\end{tabular}

Source: Complied by the authors from BCBS (2006a) 
As can be seen in Figure 1, the SA applies only prescribed (by the Regulator) risk-weights and uses very little credit-risk mitigation; the use of models is almost completely absent. The AA, on the other hand, applies more specific risk measures, for example Probability of Defaults (PDs), Loss Given Default (LGD) and Exposure on Default (EAD), and all these measures are based on comprehensive and complex mathematical models. With the FIRB, LGD and EAD and maturity $(\mathrm{M})$ are prescribed, but with the AIRB, the bank is allowed to use its own models to calculate all the components and in essence has much more freedom when it comes to calculating risk capital.

The implementation of Basel II coincides with the considerable losses reported by some of the world's largest banks (Figure 2), requiring large-scale recapitalisations (Benink \& Kaufman, 2008:2). The risk models underlying Basel II are similar to those employed by many banks (and indeed, the former may have influenced the latter). It is widely known that many models are prone to considerable weakness on account of unrealistic assumptions. Recent events have challenged the usefulness of the important elements in Basel II, as the need to recapitalise banks has revealed that many banks' internal models for both assessing credit risk and calculating risk capital performed poorly in underestimating the risk exposure (Benink \&Kaufman, 2008:2). This reflects some of the difficulties of accounting for low-probability/ high-impact events.

\section{Figure 2}

Largest bank write-downs since the beginning of 2008

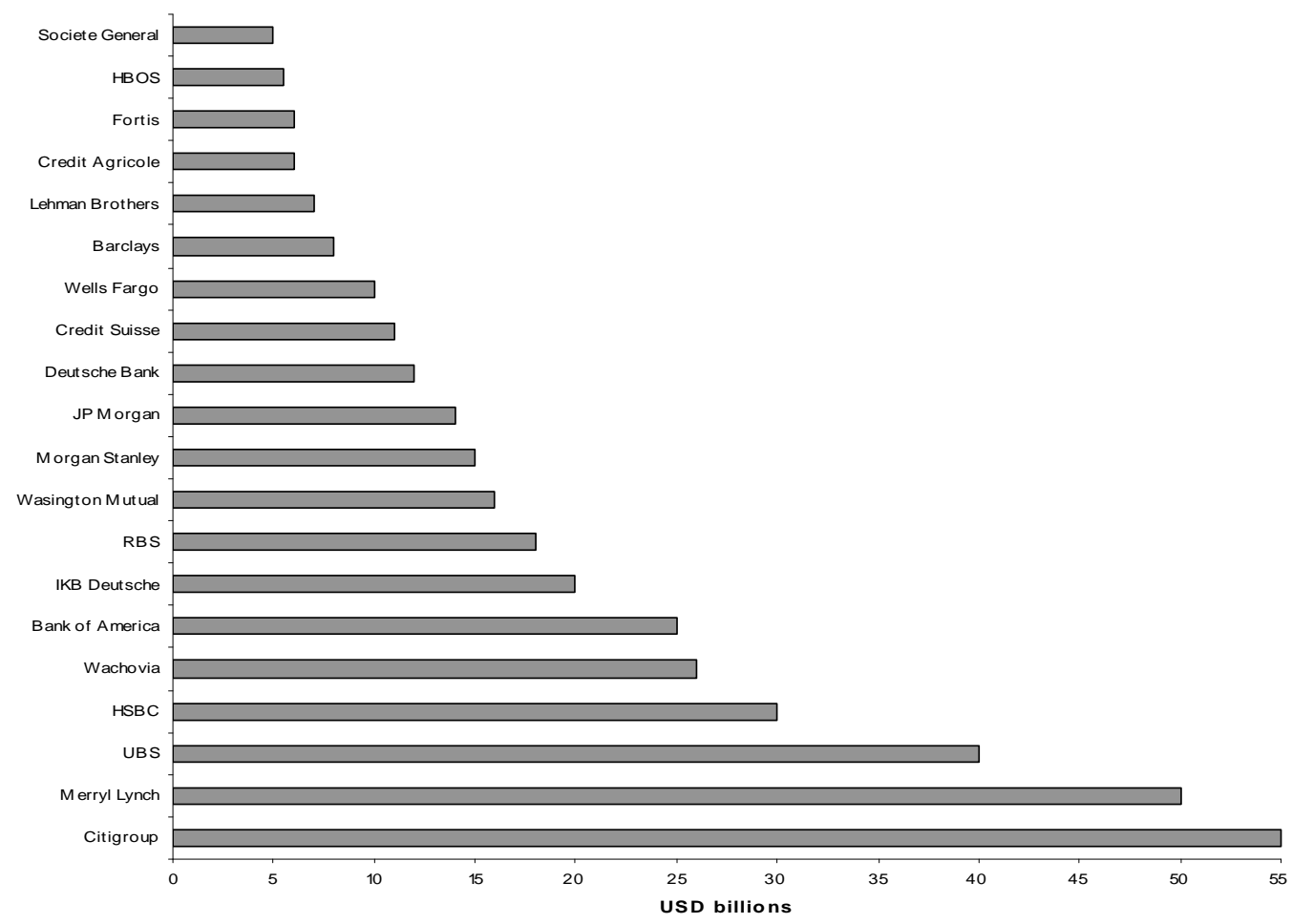

Source: Compiled by the authors from CNN Money.com

Most critics of Basel II do not oppose the accord in its entirety, but are more critical of the somewhat arbitrary 'scientific precision' imposed by the advanced approaches
(Diamond \& Rajan, 2009:1). For example, in the European Union (EU), Basel II requires banks and other financial institutions to apply an EU-formulated 'Risk Assessment Model' at 
the end of each day's trading to demonstrate solvency. If solvency cannot be established, authorities are informed and the bank ceases trading. This does not pose much of a problem in a rising market (Diamond \& Rajan, 2009:2). In a highly volatile or falling market, however, this could prove catastrophic, not least because the model fails to take into account inevitable changes in market sentiment. In addition, the short-term impact of new information is factored in, regardless of its accuracy or inaccuracy. Most models also ignore underlying asset worth (Diamond \& Rajan, 2009:2). In the UK, both Northern Rock and Bradford and Bingley fell foul of Basel II. Both banks were in the process of applying the Basel II advanced approach (Diamond \& Rajan, 2009:2).

Cannata and Quagliariello (2009:9) were among the first to criticise the assessment of credit under the advanced approaches, which rely on complex models and ratings derived from external credit rating agencies (ECRAs). The assessment of borrowers' creditworthiness provided by ECRAs is a significant aspect of the models used for assessing credit risk in the advanced approaches and there are definite doubts as to the quality and reliability of their inputs into these models (Cannata \& Quagliariello, 2009:9). The degree of independence of the rating agencies' judgement is also of major concern, which is particularly true in the case of securitisations and structured products (Zingales, 2008:12). While the 'issuer-pays' model applies to all the products, including corporate bonds, rated by these ECRAs the standard conflict of interest may be more acute for structured finance ratings, as ECRAs sometimes discuss the rating implications of particular structures during the structuring process. These conflicts are exacerbated when ECRAs also sell consulting services to entities that purchase ratings. ${ }^{4}$

Table 1 highlights the major UK banks using the advanced approaches and their sovereign support provided. Table 2 highlights the European countries that had to receive sovereign support, and also illustrates the percentage of their banks using the advanced approaches. It is clear that the majority of the banks that received support were those already using the advanced approach.

Table 1

Top UK banks that received sovereign support (with all using the Basel Advanced Approach)

\begin{tabular}{|l|c|}
\hline HBOS & $\begin{array}{c}\text { Support } \\
\text { GBP £bn }\end{array}$ \\
\hline Lloyds TSB & 11.5 \\
\hline Royal bank of Scotland & 5.5 \\
\hline Barclays Bank & 20.0 \\
\hline \% of total sovereign support & 6.5 \\
\hline
\end{tabular}

Source: Compiled by the authors from CNN Money.com

Table 2

List of European countries and the sovereign support provided

\begin{tabular}{|l|c|c|}
\hline Germany & $\begin{array}{c}\text { Support } \\
\text { US\$bn }\end{array}$ & $\begin{array}{c}\% \text { of banks using } \\
\text { advanced approach }\end{array}$ \\
\hline France & 549 & $90 \%$ \\
\hline Spain & 440 & $75 \%$ \\
\hline Austria & 137 & $70 \%$ \\
\hline Belgium & 21 & $95 \%$ \\
\hline
\end{tabular}

Source: Compiled by the authors from CNN Money.com 
Another criticism focuses on rating methodologies that play a role in the risk assessment of models under the advanced approaches. The assignment of a rating is subject to many challenges. For instance, for complex financial instruments the limitations of statistical models have become even more evident, as such products are often illiquid and, in certain market conditions, they do not have a market price (Zingales, 2008:12). In addition, the shortcomings of models based on external ratings are clear, and the need to identify possible solutions is unarguable. However, it is quite difficult at this stage to imagine plausible alternatives to the involvement of rating agencies in the assessment of credit quality. Further criticism is levelled at the lack of adequate and accurate data: historical data on the performance of US sub prime loans, for example, was confined largely to a benign economic environment with rising house prices (Cannata \& Quagliariello 2009:9). The lack of sufficient historical data or of scenario analysis that adequately assessed how particular asset pools would respond to potential economic scenarios led to errors in ratings. In particular, ECRAs underestimated the spike in correlations in the defaults that would occur during a broad market downturn (Cannata \& Quagliariello, 2009:9).

Table 1 shows the four largest banks in the UK, which received sovereign support of over $£ 30$ billion in total. This support was chiefly to absorb the considerable credit losses that had occurred since the start of the economic crisis. Table 2 illustrates the main European countries that provided sovereign support to local banks and also lists the percentage of banks which employed the AIRB approach for credit risk. It is interesting to note that, for almost all of the major European and UK banks, 85 per cent of sovereign support was provided to banks using the AIRB approach for assessing credit risk. This indicates significant shortcomings in the AIRB approach for assessing credit risk and for estimating credit risk capital. Benink and Kaufman (2008) argue that this could be due to a key, albeit incorrect, assumption that banks' internal models for measuring risk exposures are superior to any other. The AA implies perverse incentives that induce banks to underestimate their exposure to risk. ${ }^{6}$ Onado
(2008) disagrees that the market is more efficient than regulatory authorities in the detection of adequate capital levels and rejects the assumptions that banks, because of their operational expertise, are able to assess risks and their optimal capital requirements.

Furthermore, supervisors may also be partly to blame for the inadequacy of some banks' own internal credit assessment and capital calculation models, as they were required to assess and examine the robustness of these models before the bank was allowed to use them for regulatory purposes (Benink \& Kaufmann, 2008:3). This is because the assessment process was clearly new to both the banks and the supervisory authorities, requiring a gradual learning-by-doing. However, neither party had given itself enough time to really understand the ability of these models to measure, for example, rare but extremely dangerous events. In other words, regulators should have given themselves more time to assess and examine the banks' internal models before allowing them to use these for regulatory purposes. This points to the possible failure of one aspect of the Basel II advanced approaches, rather than to the entire philosophy of Basel II (Benink \& Kaufmann, 2008:3).

The incentives offered by Basel II in terms of lower capital requirements are justified only if the AIRB approach models for calculating capital and assessing credit risk are both sound and prudent (Onado, 2008). In certain countries, validation standards may have not always been sufficiently rigorous and some banks may have underestimated the importance of developing strong risk management and audit functions (Onado, 2008). An anonymous risk manager (The Economist, 2008:12) stated that:

[a]t the root of it all, was and still is, a deeply ingrained flaw in the credit decision making process. In contrast to the law, where two sides make an equal-and-opposite argument and is fairly judged, in banks there is always a bias towards one side of the argument. The business line was more focused on getting a transaction approved than on identifying the risk in what it was proposing. Often in meetings our gut reactions as the risk managers were negative, but it was difficult 
to come up with hard-and-fast arguments for why you should decline a transaction, especially when you were sitting opposite a team that had worked for weeks on the proposal. In the end, with pressure for earnings and a calm market environment, we reluctantly agreed to marginal transactions.

Another criticism of banks' advanced risk assessment methods is that they would privilege the use of standardised and quantitative information, neglecting the soft information that is a key driver in the bank-customer relationship (Cannata \& Quagliariello, 2009:9). This problem should not be underestimated: complex rating methodologies developed by banks for the Basel II AIRB approach focus too often on quantitative data, disregarding the enormous amount of qualitative information on borrowers, which cannot easily be incorporated into statistical and mathematical models. A more widespread use of quantitative techniques for measuring and assessing credit risk also tends to make the relationship between banks and firms more transparent.

It is worthwhile explaining the major differences between the Basel II standardised and advanced approaches (Figure 1). Basel II makes use of two approaches to credit risk, including the Standardised Approach (SA) and the Internal Ratings Based (IRB) approach, which is further subdivided into the Foundation IRB (FIRB) and the Advanced IRB (AIRB) ${ }^{7}$ (Styger \& Vosloo, 2005:10). With the SA, banks may not use any internal models. This approach is similar to that of
Basel I, in which each exposure is assigned a risk weight based on the characteristics of the specific loan (Styger \& Vosloo, 2005:10). A corporate borrower's credit quality is reflected by its external rating as assigned by an external rating agency, and, if there is no external rating, the loan's risk is generally weighted by 100 per cent (us under Basel I) and a retail exposure (individual) is generally weighted at 75 per cent (Styger \& Vosloo, 2005:11). However, lending that is fully secured by mortgages on residential property that is (or will be) occupied by the borrower, or that is rented, may be risk weighted at 35 per cent (Styger \& Vosloo, 2005:11). This approach is fairly uncomplicated and differs substantially from the advanced approaches.

Both the FIRB and AIRB approaches are based on risk components, which include Probability of Default (PD), Loss Given Default (LGD) and Exposure at Default (EAD). All these are based on estimates calculated using mathematical/statistical models that employ the bank's own default history to determine these estimates (Styger \& Vosloo, 2005:12). A corporate or individual borrower's credit quality is assessed according to the product of the above three estimates, where PD is the possibility (as a percentage) that the borrower will default, EAD is the exposure of the bank at the time of borrower default and LGD measures the actual loss after all losses have been realised, including legal fees (if any) (Styger \& Vosloo, 2005:12). Table 3 provides a summary of the differences between the FIRB and AIRB approaches.

Table 3

Risk estimates with FIRB and AIRB approach

\begin{tabular}{|c|c|c|}
\hline & \multicolumn{2}{|c|}{ IRB approach } \\
\hline & FOUNDATION & ADVANCED \\
\hline PD & \multicolumn{2}{|c|}{ Bank calculates } \\
\hline LGD & \multirow{2}{*}{ Prescribed by the Regulator } & \multirow{2}{*}{ Bank calculates } \\
\hline EAD & & \\
\hline
\end{tabular}

Source: Complied by the authors from BCBS (2006a)

The Basel II AIRB approach relies heavily on calculations from models, in most cases complex and technical, that employ banks' past default history. It is these estimates that are under the spotlight as potential causes of the credit crisis. Banks have been accused of neither possessing nor employing adequate loss history on which to base their models, as well as not adequately stress-testing these models to assess the possibilities of extreme 
losses, such as those experienced in the crisis. In some cases financial engineers involved in model construction simply did not comprehend the true characteristics of rapidly changing markets.

In order to test the truth or falsehood of the above accusations, the next section evaluates credit losses experienced by global banks using (a) the SA and (b) the AA to assess credit risk prior to and during the crisis. This evaluation will assist in the determination of the more successful approach in the assessment of (and hence mitigation of) credit risk. The analysis proceeds via the construction of severity and frequency distributions for both sets of data before and during the credit crisis.

\section{3}

\section{Credit loss distributions and data}

The BCBS classification of the credit risk loss severity distribution is shown in Figure 3. Expected losses should be covered by pricing and provisioning; unexpected losses require regulatory credit risk capital. Basel II requires the credit risk capital charge to target unexpected losses and capture tail events (BII 2009:3) at the $99.9^{\text {th }}$ percentile. Banks must either insure or face the consequences of losses beyond this percentile.

Figure 3

Important features of a typical credit loss distribution

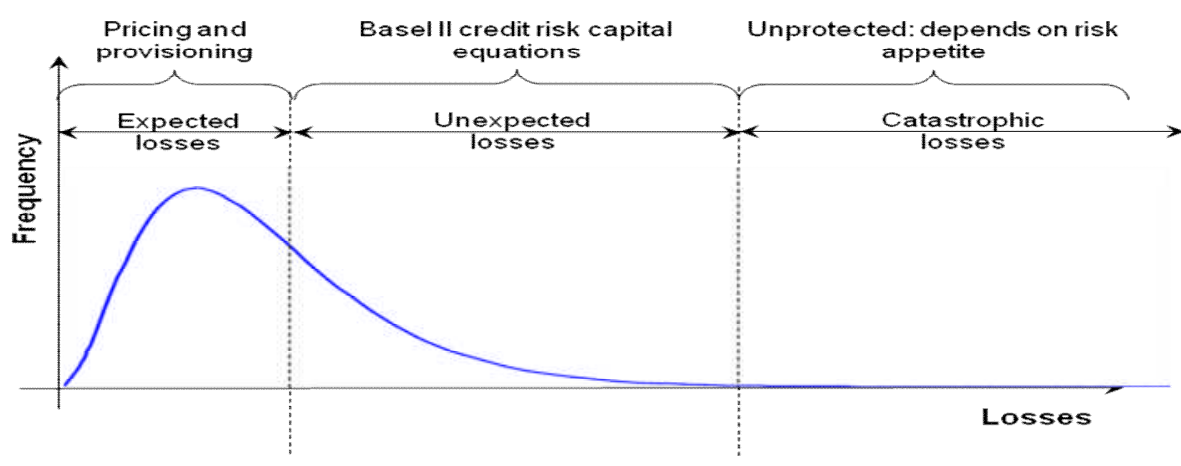

Source: Bll (2009:2)

The choice of July 2007 as the start of the credit crisis was justified in part by the firstarticle, which mentions the credit crisis by name (Moneyweek, 2007), but also by subsequent analysis, which has shown that severe signs of weakness were evident and becoming manifest by late July 2007 (Daily Kos, 2009). The credit-risk loss data were procured from eight international retail banks through Standard and Poor's LossStats ${ }^{\circledR}$ Database, four of which apply the $\mathrm{SA}$, while the other four apply the AA for assessing credit risk. Only minor problems were experienced with the data, as the database from which these were sourced provided more than enough data points in order to perform an adequate analysis. However, all losses less than ZAR100, 000 were excluded, which reduced the data pool quite significantly.
BEFORE THE CRISIS: Benign from an economic point of view, the 4.5-year period from January 2003 to June 2007 was characterised by low interest rates, low inflation, relatively new bank regulations regarding operational risk, explosive growth of credit and other derivatives, considerable loan securitisations, a huge demand for commodities such as oil and metals from India and China and low unemployment.

DURING THE CRISIS: The turbulent twoyear period from July 2007 to the present (June 2009), that is, from the onset of the credit crisis and characterised by almost non-existent interest rates, hugely diminished stock markets, increasing taxes, a severe regulatory environment for, inter alia banks, regulators and rating agencies and rising unemployment.

High-level loss characteristics are sum- 
marised in Table 4 and a comparison is made between the average number of losses for the banks as well as the value using the SA and AA before and during the crisis.

Table 4

Credit losses by Basel II approach to credit risk pre- and during the credit crisis

\begin{tabular}{|l|c|c|c|c|}
\hline \multirow{2}{*}{ ZAR } & \multicolumn{2}{|c|}{ Standardised } & \multicolumn{2}{c|}{ Advanced } \\
\cline { 2 - 5 } & Before & During & Before & During \\
\hline Total value & $1.57 \mathrm{bn}$ & $1.11 \mathrm{bn}$ & $0.90 \mathrm{bn}$ & $1.64 \mathrm{bn}$ \\
\hline Total number & 1,490 & 1,629 & 1,035 & 723 \\
\hline Average per year & $1.05 \mathrm{mn}$ & $1.19 \mathrm{mn}$ & $0.87 \mathrm{mn}$ & $2.28 \mathrm{mn}$ \\
\hline Maximum loss & $29 \mathrm{mn}$ & $37 \mathrm{mn}$ & $20 \mathrm{mn}$ & $42 \mathrm{mn}$ \\
\hline Average number per year & 331 & 465 & 230 & 362 \\
\hline
\end{tabular}

Source: Compiled by the authors from S \&P's LossStats ${ }^{\circledR}$ Database

Figure 4

Comparison of loss averages pre- and during the crisis
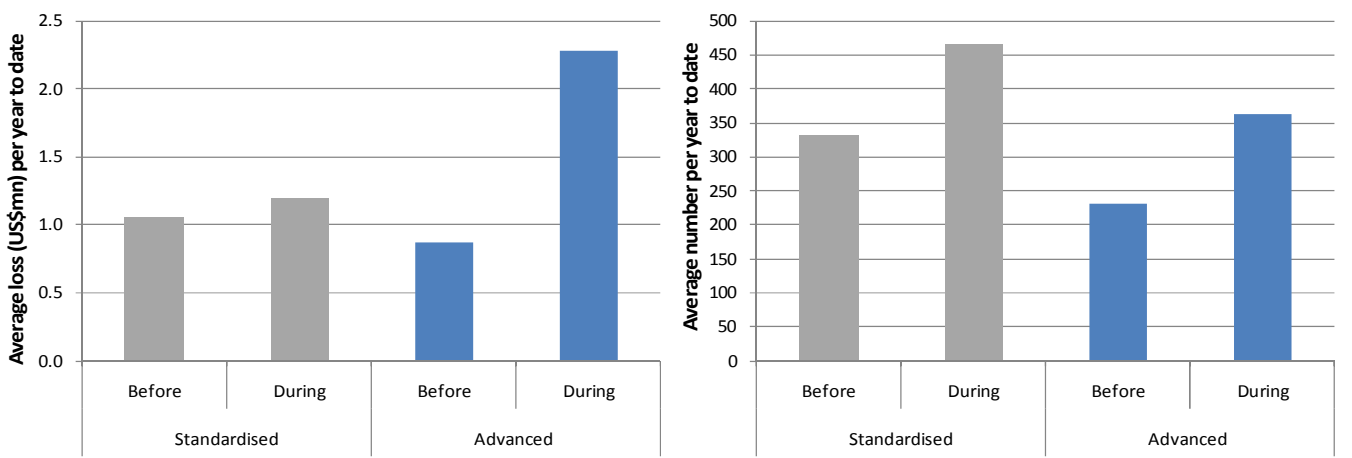

Source: Compiled by the authors from S \&P's LossStats ${ }^{\circledR}$ Database

The average severity of credit losses increases for banks using both the SA $(+13$ per cent $)$ and the AA (+162 per cent) from before to during the crisis (also see Table 4). The average frequency of losses also increases for both the SA ( +40 per cent $)$ and the AA ( +57 per cent).

\section{4}

\section{Analysis}

Figure 5 shows the frequency and severity of bank credit losses for banks using the SA. The onset of the credit crisis is indicated by a dashed line.

The average frequency of credit losses for banks using the SA in Figure 5(a) increases, which can be seen in Figure 4 as well, where the average number of losses per year also shows an increase from 331 to 465 losses per year (40 per cent increase). However, there is very little movement in the severity of these losses before and during the crisis, as illustrated by Figure 4 and Figure 5(b). In summary, Figure 4 illustrates that, although the average frequency has increased, the average severity has not increased by the same magnitude.

However, the same cannot be said for the credit losses for banks using the AA, as illustrated in Figures 6(a) and (b). Figure 6(a) clearly indicates that there has been a significant increase in the average number of credit losses experienced during the crisis, which is further illustrated in Figure 4, in which the average number of losses per year increased from 230 to 362 , a 58 per cent increase. 
Figure 5

Monthly credit loss (a) frequency and (b) severity for the periods under investigation for banks using the SA
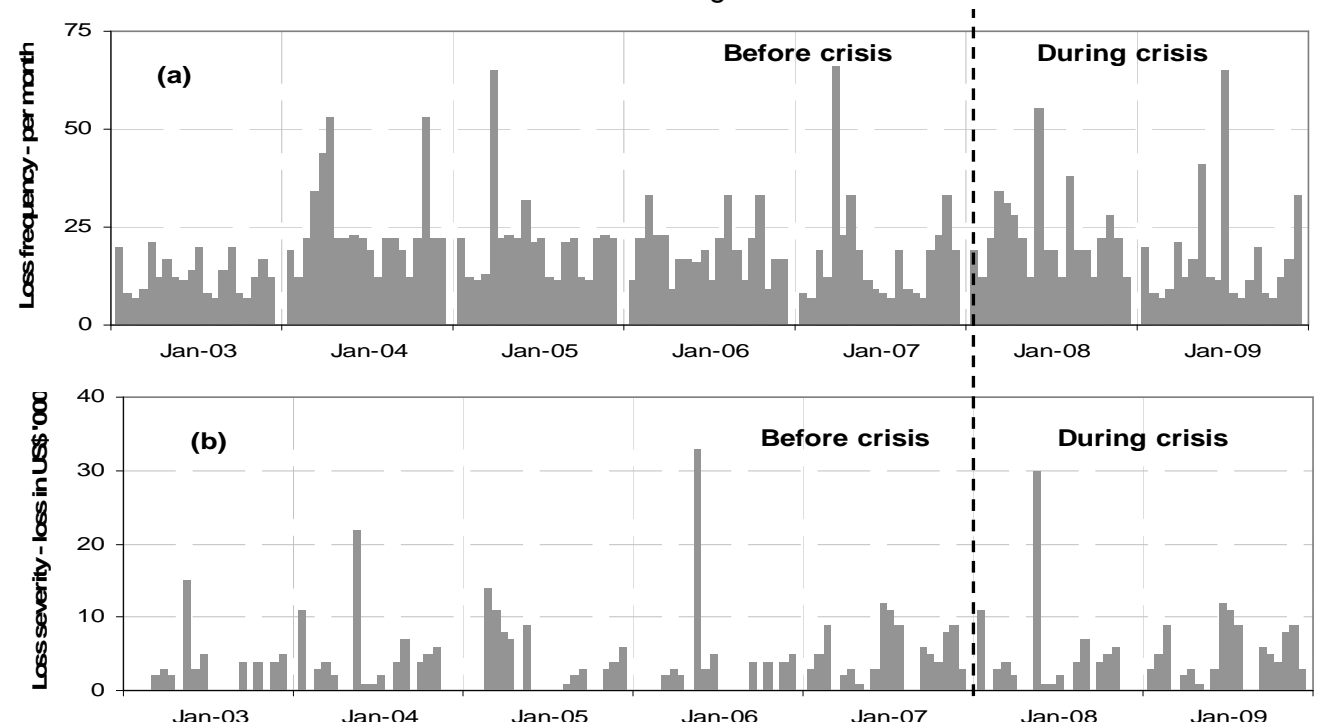

Source: Compiled by the authors from S \&P's LossStats ${ }^{\circledR}$ Database

Figure $6 a$ and $b$

Monthly credit loss (a) frequency and (b) severity for the periods under investigation for banks using the AA
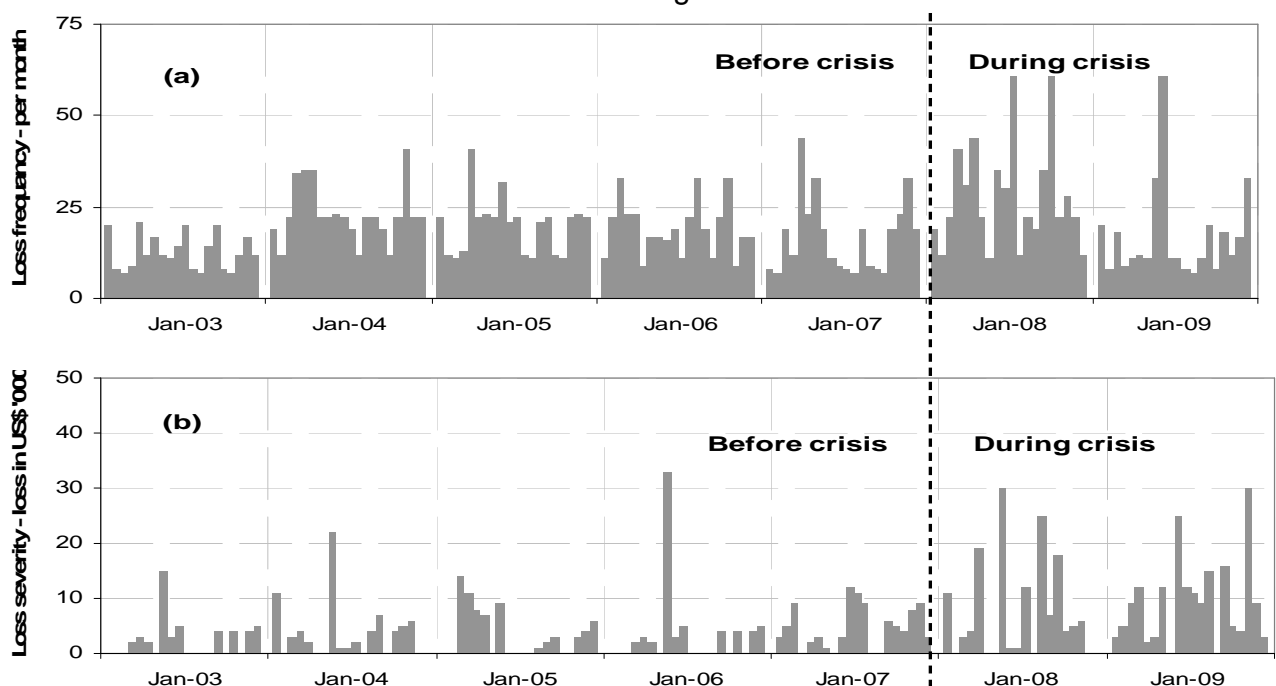

Source: Compiled by the authors from S \&P's LossStats ${ }^{\circledR}$ Database

Frequency distributions of loss events measured as events per month, for banks using the SA before and during the crisis are shown in Figures 7(a) and (b) respectively. These show many similarities - a concentration of low-severity losses and a few large outliers, or tail events. The inter-arrival time of loss events for banks using the SA, also measured before and during the crisis, are shown in Figures 8(a) and (b) respectively. Before the crisis, the loss events were evenly distributed, the majority of them occurring between 10 to 15 days of each 
other. During the crisis the distribution becomes bimodal, with prominent peaks in the five and 10 day categories. Both Figures 7(a) and (b) and Figures 8(a) and (b) again illustrate that the frequency of losses for banks using the $\mathrm{SA}$ showed an increase during the crisis.

Figure $7 a$ and $b$

Loss severity for banks using the SA - histograms and distributions for the period (a) January 2003 to June 2007 and (b) July 2007 to July 2009
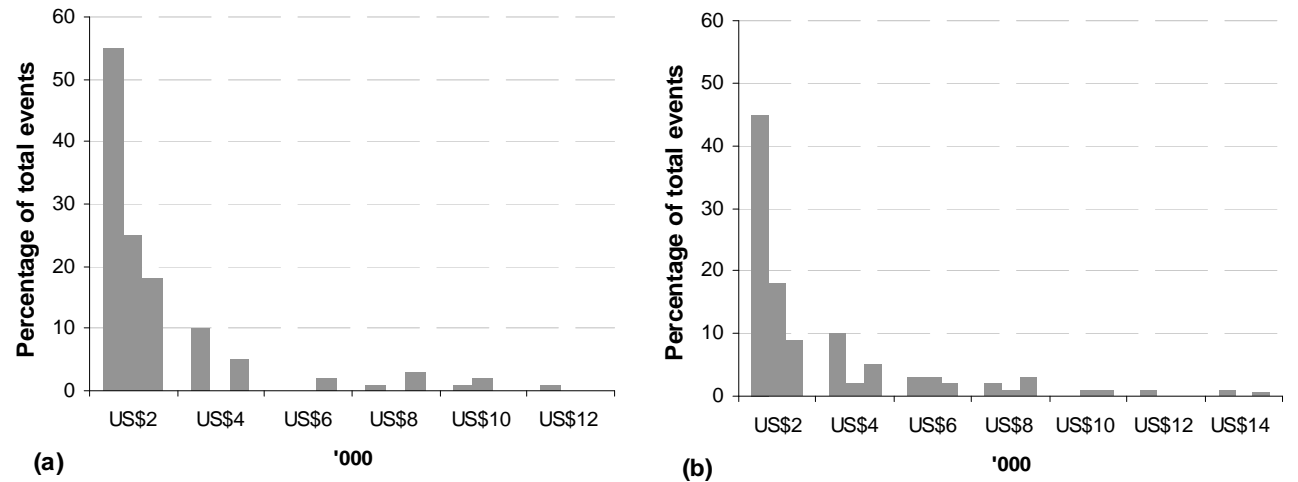

Source: Compiled by the authors from S \&P's LossStats ${ }^{\circledR}$ Database

Figure 8

Inter-arrival time distribution of credit losses for banks using the SA for the period (a) January 2003 to June 2007 and (b) July 2007 to July 2009

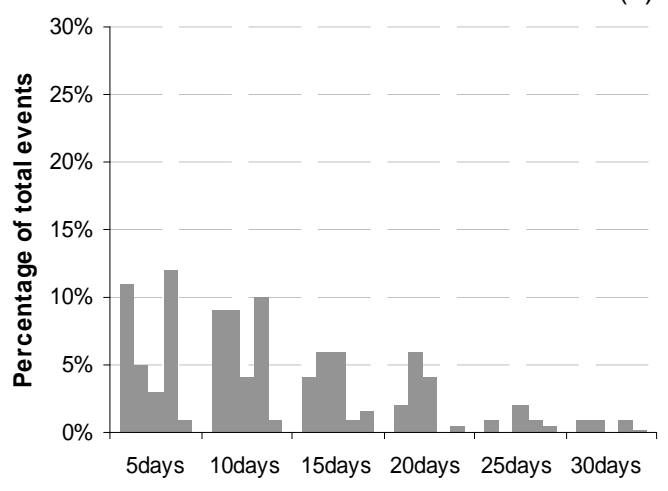

(a)

Days between events

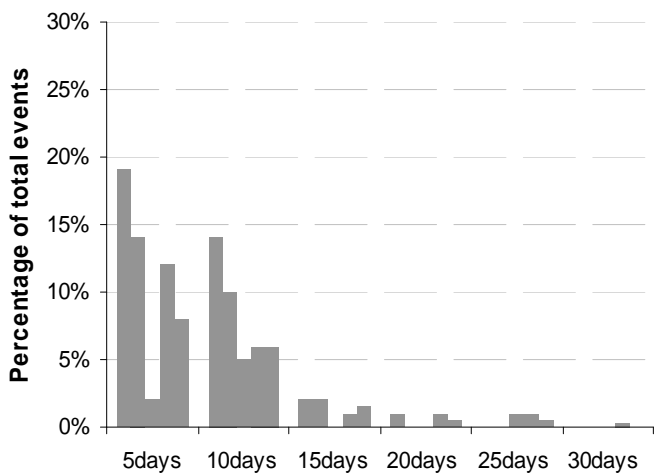

(b)

Days between events

Source: Compiled by the authors from S \&P's LossStats ${ }^{\circledR}$ Database

The frequency distribution of loss events, measured as events per month, for banks using the AA before and during the crisis, is shown in Figures 9(a) and (b) respectively. Both these show a concentration of lowseverity losses. Figure 9(b), however, shows significant increases in the number of outliers, that is, tail events, indicating an increase in severity. The inter-arrival time of loss events for banks using the AA, also measured before and during the crisis, are shown in Figures 10(a) and (b) respectively. Before the crisis, the loss events were evenly distributed, the majority occurring within 10 to 20 days of each other. During the crisis, the distribution becomes bimodal, with prominent peaks in the five and 10-day categories. Figures 9(a) and (b, and Figures 10(a) and (b), illustrate that both the frequency and the severity of losses for banks using the AA increased during the crisis. 


\section{Figure 9}

Loss severity for banks using the AA - histograms and distributions for the period

(a) January 2003 to June 2007 and (b) July 2007 to July 2009
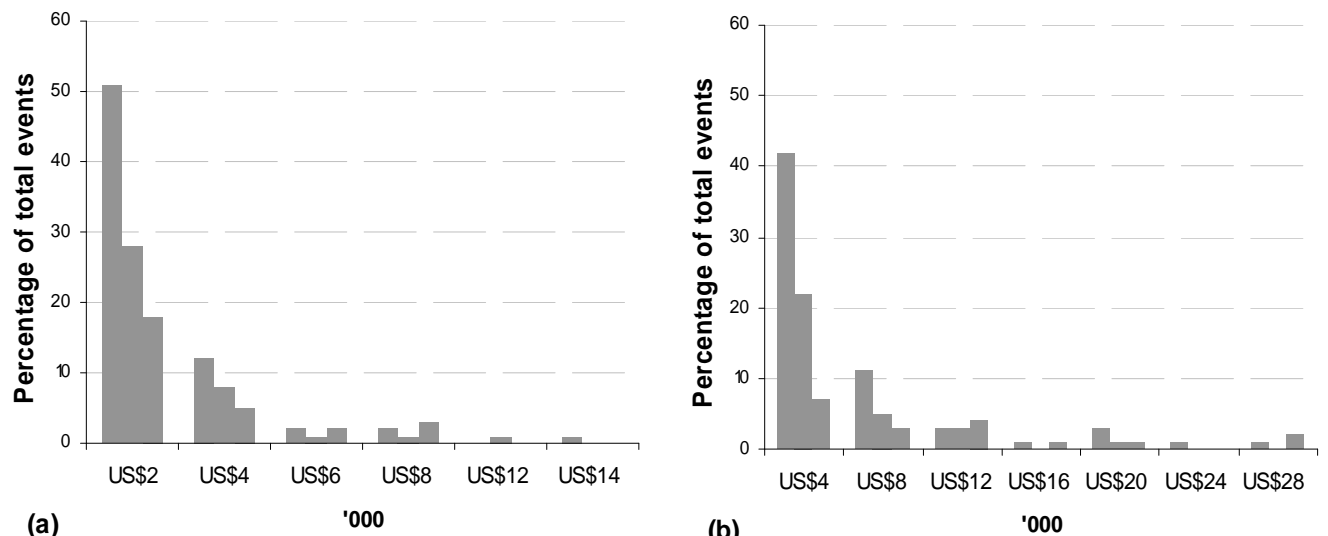

(b)

'000

Source: Compiled by the authors from S \&P's LossStats ${ }^{\circledR}$ Database

Figure 10

Inter-arrival time distribution of credit losses for banks using the AA for the period (a) January 2003 to June 2007 and (b) July 2007 to July 2009

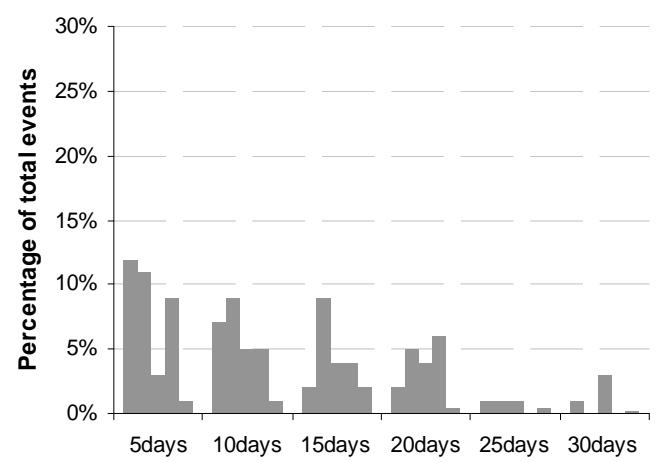

(a)

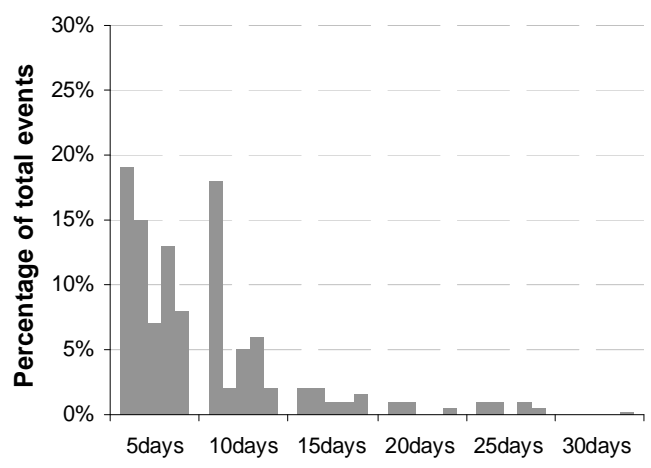

(b)

Days between events

Source: Compiled by the authors from S \&P's LossStats ${ }^{\circledR}$ Database

In summary, although most banks experienced an increase in the number and value of credit losses, the Basel II approaches did protect banks during the financial crisis. However, it can clearly be seen that the SA was much more successful than the AA. This was because, although the frequency of losses increased for banks suing the SA, the severity remained relatively the same. However, the same cannot be said for banks using the AA, as the frequency increased but the losses also became much more severe, which was not the case with the SA. 
Table 5

Summary statistics and goodness of fit test results of the frequency and severity distributions respectively

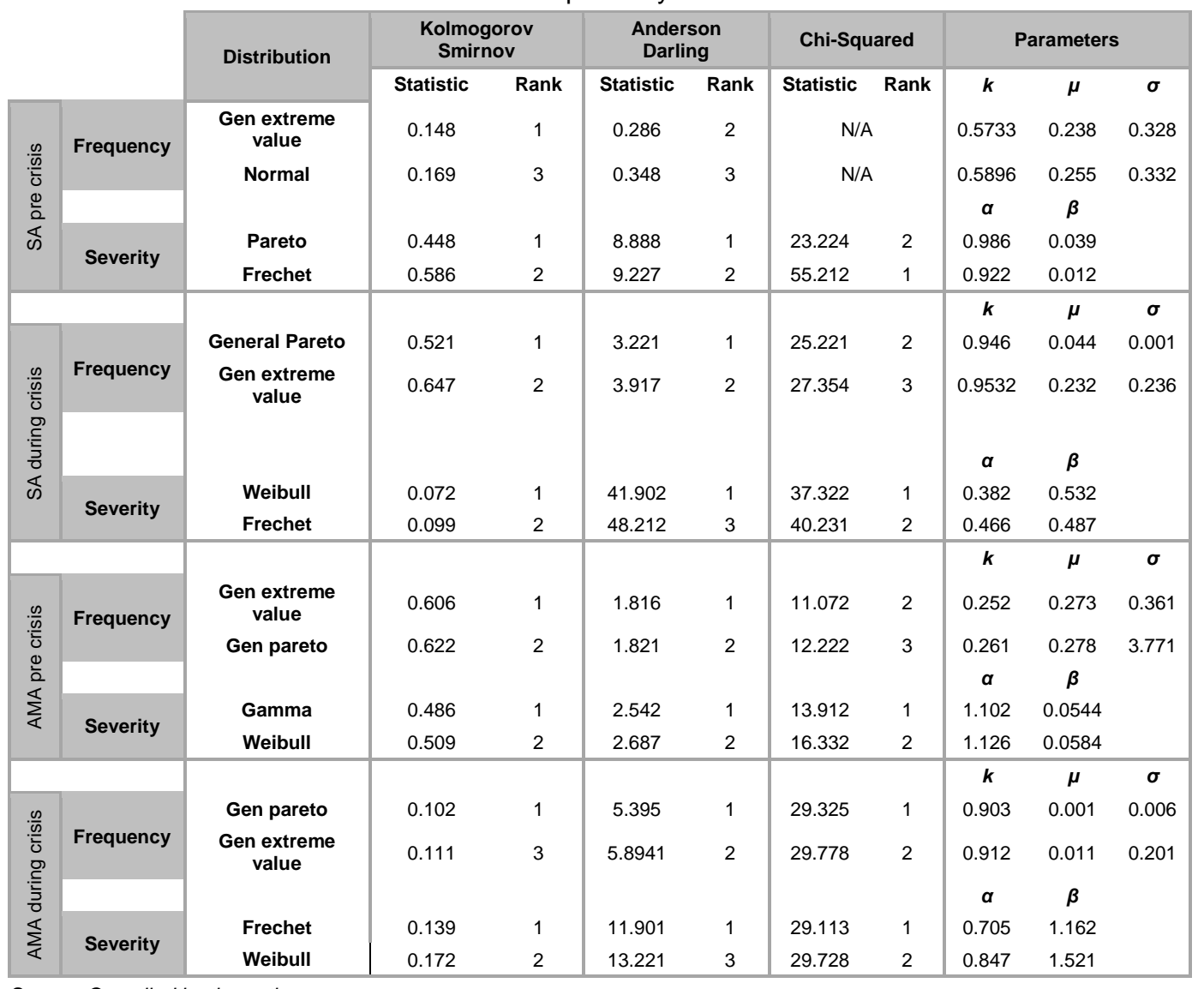

Source: Compiled by the authors.

In Table 5 above, three different 'fitting techniques' were used to determine which distribution best fitted the data. A ranking was allotted to each. This means that the distribution with the lowest ranking of the three techniques best fitted the data. This technique helps to determine which distribution is best to use for modelling a severity and frequency distribution to a specific dataset. This paper has found that the General Extreme Value Distribution best fits the frequency distribution, while the Frechet Distribution best fits the severity distribution. Although the Gamma Distribution and the General Pareto Distribution also fit the data well, as indicated in Table 5, the authors decided to use the above distributions, as their previous distributions were carried out via these and they have shown the required accuracy and reliability. It is recommended that future research use the other distribution approaches. The above added value to the outcome of this study, as it assisted the authors in identifying the best approach to use in transforming the data into meaningful results.

\section{5}

\section{Conclusion}

Since the start of the economic crisis in July 2007, numerous banks have written down substantial credit losses, and in many cases have failed completely. Criticism has been levelled at, inter alia, Basel II's methods of measuring credit risk: it is widely believed that the complex advanced approaches are too 
complex, and that they introduce perverse incentives to banks, permit 'capital allocation arbitrage' and encourage lax lending standards. This paper investigated the soundness of the Basel II approaches to assessing, measuring and managing credit risk during two very different periods of market stability - before and during the ongoing credit crisis. Whether the methods were satisfactory in assigning adequate capital fell outside the scope of this paper; attention was instead focussed on the methods of assessing credit risk.

The literature research and investigation conducted for this paper found that most of these methods of assessing credit risk under the advanced approaches were based on complex mathematical and statistical principles. However, it was not the principles that were being challenged but the suitability of the methods for 'adapting' to extreme market conditions. Some of the possible reasons discussed in this paper for the failure of these advanced methods include the lack of adequate 'stressed' data and over-reliance on external parties, for example, rating agencies and auditing firms, who themselves were reliant on mathematical and statistical data to provide guidance to banks ${ }^{8}$. In addition, the financial engineers responsible for model construction were mathematically competent but economically naive, unable to comprehend the impact and the knock-on effects of extreme market conditions and the inadequate time allowed between model construction and testing and model implementation by banks. Furthermore, the ability of these models to adjust in very volatile markets and the signingoff by regulators of internal models and methods who themselves did not always understand the model machinations can also be seen as possible reasons for the failure of these advanced methods.

To assess whether the methods employed under the SA were more successful than those employed under the AA, data were sourced from eight international retail banks (four using the SA and four using the AA approach). The frequency and severity distributions of credit losses from these banks were produced and analysed. For banks using the SA, the average frequency increased from before to during the crisis. However, the average severity remained stable, with only a slight increase in the average value. For banks using the AA, the average frequency and average severity increased from before to during the crisis, which means that not only did the average number of events increase, but they also became much more severe.

The implication is that, although several market participants were eager to blame Basel II for the financial crisis, it can be said that, in most cases, compliance with the Basel II accord actually protected banks during the economic crisis. The SA enjoyed greater success than the AA: the main reason for the failure of the AA resided in the complex methods on which it relied to assess credit risk.

Many banks, while continuing to meet the minimum requirements of Basel I, had already reviewed their credit standards in order to make them consistent with the incoming Basel II discipline (and ultimately being Basel II AA complaint). It is therefore likely that some banks, in an attempt to transform wellestablished credit processes and risk management methods may have misjudged the actual exposures to new risk types or new manifestations of traditional risks. This does not imply that the new framework should be discarded, but rather that it confirms the need for the 'testing' phase of the new rules to be more rigorous. Furthermore, regarding simplified supervisory tools, such as the 'leverage ratio', which are becoming increasingly popular, the authors believe that these are likely to raise the same problems as those posed by Basel I, for instance, the low sensitivity to risk. While it cannot exclude the fact that such tools could be used as a complement to Basel II, especially during periods of stress, when internal models are not fully reliable, the authors are sceptical of the idea that they could serve as a complete substitute for a risk-sensitive regulation.

The solution may not lie in drafting new rules under Basel III, but possibly in less of a reliance on complex mathematical and statistical models when assessing credit risk, along with more focus on experience and client knowledge. 
1 These catastrophes could include large credit losses or a liquidity shortage / mismatch, which could bring about a bank's failure. Central banks were excluded from the focus of this paper since they do not have to comply with Basel II.

2 It is the subject of some debate as to the initial event that triggered the 'credit crisis'. See section 2 for a more detailed discussion of and qualifying arguments for the author's choice of mid-2007. Furthermore, since the time of writing (January 2010) and despite some evidence of 'green shoots of recovery', the crisis is arguably far from over. Lending practices remain severely curtailed, stock markets are still below their pre-crisis highs, most economies remain in the grip of recession and many banks continue to be supported by their sovereigns.

3 Discussion document presented at the IMF's ninth annual Jacques Polak Research Conference in Washington, November 2008.

4 Zingales (2008:1) pointed out that it is a mistake to think that the significant power attributed to these new mechanisms to these institutions would not have affected the independence of their judgment, because, as power corrupts, absolute power corrupts absolutely. Rating agencies are no exception to this rule.

5 Barclays Bank never received sovereign support, but this is the amount that was raised internally to prevent collapse and is therefore included here.

6 Basel II creates perverse incentives to underestimate credit risk. Because banks are allowed to use their own internal models for assessing risk and determining the amount of regulatory capital, they may be tempted to be overoptimistic about their risk exposure in order to minimize required regulatory capital (Benink \& Kaufman, 2008:2).

7 As both these approaches are considered much more advanced than the SA, they are both considered in this paper as being 'advance' (AA).

8 This paper by no means implies that rating agencies or audit firms were to blame for the failure of the advanced approaches, but more that banks and other financial institutions were too reliant on their input and did not use enough internal resources to build and test these methodologies.

\section{References}

ALLEN, L. \& BALI, T. 2007. Cyclicality in catastrophic and operational risk measurements, Journal of Banking and Finance, 31:1191-1235.

BCBS. 2006a. International convergence of capital measurement and capital standards, Bank of International Settlements. [Online] Available at: http://www.bis.org/publ/bcbsc111.htm [Accessed 2009-06-22].

BCBS. 2009. Consultative proposals to strengthen the resilience of the banking sector announced by the Basel Committee, Bank of International Settlements. [Online] Available at: http://www.bis.org/press/ p091217.htm [Accessed 2010-01-11].

BENINK, H. \& KAUFMAN, G. 2008. Turmoil reveals the inadequacy of Basel II, Financial Times, 28 February 2008.

BII, 2009. BIS2 - Best practices for BIS 2 implementation. [Online] Available at: http://bis2information. org/content/Credit_Loss_Distribution [Accessed 2009-10-05].

CANNATA, F. \& QUAGLIARIELLO, M. 2009. The role of Basel II in the sub-prime financial crisis: guilty or not guilty? Garefin Working paper. University of Bocconi, Milan, Italy.

CNN MONEY.COM. 2009. List of Bailed out Banks. [Online] Available at: Http://money.cnn.com/news/ specials /storysupplement/bankbailout/ [Accessed 2009-10-08].

COLANDER, D., FOLLMER, H. \& HAAS, A. 2009. The financial crisis and the systematic failure of economics. Kiel working paper. Kiel Institute for the World Economy. Kiel, Germany.

DAILY KOS, 2009. When did the financial crisis really start? [Online] Available at: http://www.dailykos.com/story/2009/2/12/125228/516/46/696617 [Accessed 2009-08-01].

DIAMOND, D.W. \& RAJAN, R.D. 2009. The credit crisis: conjectures about causes and remedies, American Economic Review, American Economic Association, 99(2):606-60.

GRIFFIN, C. 2008. Basel II capital, adequacy regulations and the credit crisis - cause or cure? [Online] Available at: http://www.charteredaccountants.ie/en/Members/Technical1 [Accessed 2009-09-04].

MONEYWEEK. 2007. Is this the start of the credit crisis? [Online] Available at:

http://financialmediaandcomms.blogspot.com/2008/09/global-credit-crunch-when-did-it-start.html [Accessed 2009-05-19].

ONADO, M. 2008. Capital is a problem. [Online] Available at: http://www.lavoce.info [Accessed 2009-09-19].

REPULLO, R. \& SUAREZ, T. 2008. The procyclical effects of Basel II. IMF Ninth Annual Jacques Polak Research Conference, IMF, Washington DC. [Online] Available at: http://www.imf.org/external/np/siminars [Accessed 2009-11-13]. 
SOROS, G. 2008. The new paradigm for financial markets: The credit crisis of 2008 and what it means, Public Affairs, USA, 15 May 2008.

STYGER, P. \& VOSLOO P.G. 2005. The banker's guide to the Basel II framework. The Banking Association of South Africa, Johannesburg, SA.

SUBRAMANIAN, A. 2009. The world crisis: reforming the international financial system. Economic and Political Weekly, Mumbai, India. [Online] Available at: http://www.piie.com/publications/papers/ subramanian [Accessed 2009-09-02].

THE ECONOMIST. 2008. Confessions of a risk manager, August $7^{\text {th }} 2008$.

ZINGALES, L. 2008. La sospensione del market-to-market (The suspension of market-to-market), Il Sole24 Ore, 15 October (translation from the Italian version). 